EXTENDED REPORT

\title{
Acute orbital effects of retrobulbar injection on optic nerve head topography
}

\author{
Y Akar, K C Apaydin, A Ozel
}

Br J Ophthalmol 2004;88:1573-1576. doi: 10.1136/bjo.2004.044677

See end of article for authors' affiliations

\section{Correspondence to:}

Correspondence to:
Yusuf Akar, MD, Akdeniz University, School of Medicine, Department of Ophthalmology, Antalya07070,Turkey; yakar@ akdeniz.edu.tr

Accepted for publication 19 April 2004
Aim: To assess the effects of acute orbital volume changes after retrobulbar injection on optic nerve head topography.

Methods: The study population consisted of 95 patients with type 2 diabetes mellitus with clinically significant macular oedema who required focal pattern laser photocoagulation therapy in one eye. Before each laser treatment, 49 patients required a retrobulbar injection (approximately $7 \mathrm{ml}$ of a mix of lidocaine $2 \%$ with epinephrine and bupivacaine $0.75 \%$ in equal volumes) to provide ocular akinesia. Both eyes of all patients underwent optic nerve head topographic analysis once before laser treatment (within 30 minutes), and repeated within 1 hour, 1 day, 1 week, 2 weeks, and 4 weeks after treatment, respectively. Topographic analyses were performed using a confocal scanning laser ophthalmoscope, HRT-II. The disc area, topography standard deviation, and a total of 12 topographic parameters were calculated by HRT-II.

Results: The mean age of the patients was 37.9 (SD 3.2) years. The mean disc area of the subjects was $2.12(0.44) \mathrm{mm}^{2}$. Fellow eyes which were not treated with laser, and those treated eyes which did not receive retrobulbar injection before therapy were found not to reveal significant changes in disc topography in any of the examinations (all $p$ values $>0.05$ ). In the topographic examinations in the first hour, first day, and first week, laser treated eyes which underwent retrobulbar injection demonstrated significant increase in the disc area, rim area, rim volume, rim area/disc area, and cup shape measure parameters while optic cup parameters significantly decreased (all $p$ values $<0.05$ ). In the second week examinations, they did not show significant difference in disc area measurements $(p>0.05)$. By the fourth week, all of the optic nerve head topographic variables were not significantly different from the preinjection values (all $p$ values $>0.05$ ). Colour stereoscopic photographs did not reveal any differences in optic disc appearance.

Conclusion: Acute orbital volume change following retrobulbar injection may cause significant topographic evidence of optic disc oedema lasting approximately 1 week. Significant changes in optic rim and cup area may last for 2 weeks after injection, with all topographic changes returning to baseline by 1 month after injection. The present findings could be a model to reflect the pathological processes that occur in cases of acute orbital volume changes such as retrobulbar haemorrhage.
C hanges in the optic nerve head topography occurring with chronic intraocular pressure increase have been extensively studied. ${ }^{2}$ Optic nerve head topography obtained with confocal scanning laser ophthalmoscopes was used to detect glaucomatous changes many years before functional visual field changes. ${ }^{3}{ }^{4}$ However, studies evaluating the changes in the optic nerve head topography caused by acute intraorbital pressure increase have been lacking. Bleeding such as retrobulbar haemorrhage into the intraorbital space may cause acute visual loss by compressing the optic nerve and its vascular supply. ${ }^{5}$ The emergent need for intervention (for example, lateral tarsorrhaphy and administration of intraocular pressure lowering agents) as well as the retrospective nature of most case series limits the ability to determine accurately the morphological effect of retrobulbar fluid on optic disc structure. In the current study, we attempted to evaluate how acute orbital volume increase following retrobulbar injection affected optic nerve head topography during a 4 week period.

\section{MATERIAL AND METHODS}

Both eyes from a series of 95 of 263 consecutive patients with clinically significant macular oedema (CSMO) who required focal laser photocoagulation therapy in one eye were enrolled in the study. Informed consent was obtained from each participant. The institutional review board approved the study.

Patients were excluded for any of the following criteria: ( 1 ) best corrected visual acuity less than 20/60, (2) any corneal or lens opacities, (3) history of ocular hypertension or glaucoma, a family history of glaucoma, (4) intraocular pressure readings greater than $22 \mathrm{~mm} \mathrm{Hg}$, (5) optic disc areas outside the range of $2-2.25 \mathrm{~mm}^{2}$, (6) any evidence of strabismus, or failure to maintain central fixation in any of examinations, (7) a history of any ocular trauma, surgery, laser therapy, or retinal disease other than diabetic maculopathy with or without mild non-proliferative retinopathy, (8) more than 1 dioptre of cylindrical and 5 dioptres of spherical refractive error, (9) those with dyschromatopsia, (10) age more than 50 years, (11) proptosis, and (12) anioscoria. All patients were treated with focal argon green laser photocoagulation, in a single session, according to ETDRS guidelines (including ETDRS indications for follow up treatment). ${ }^{6}$

Laser treated eyes $(n=95)$ of all patients had CSMO as defined by the ETDRS, ${ }^{6}$ with no or mild ${ }^{7}$ non-proliferative background diabetic retinopathy findings. Fellow nontreated eyes $(n=95)$ of all patients had no or mild $^{7}$

Abbreviations: CSMO, clinically significant macular oedema; HRT, Heidelberg retinal tomography 
non-proliferative background diabetic retinopathy findings with mild macular oedema which was not clinically significant. ${ }^{6}$ Fluorescein fundus angiography was performed in all patients using $5 \mathrm{ml}$ of $10 \%$ fluorescein injected intravenously. All laser treated eyes had an exudative type of maculopathy and good capillary perfusion.

All patients had type 2 diabetes with relatively short disease duration (range 3-8 years duration). All but 11 patients (six in injection, and five in non-injection group), had good metabolic control with blood glucose levels within normal limits. Cooperation of the patients in the injection group was not ideal to apply focal laser photocoagulation without the addition of the retrobulbar anaesthesia.

Before anaesthesia and laser treatment, we evaluated the best corrected visual acuity using Snellen charts, determined refractive error, performed biomicroscopic examination, measured intraocular pressure by Goldmann applanation tonometry twice, and examined the optic disc and fundus with a $78 \mathrm{D}$ lens. Keratometry was performed for all subjects. Standard achromatic visual field testing was performed (Humphrey Instruments Inc, Model 750, San Leandro, CA, USA) using full threshold strategy and the central 30-2 program. All subjects underwent perimetric examinations at least twice. Colour vision testing was performed using the Ishihara colour plates. Hertel exophthalmometric measurements were performed in cases that were suspected of having proptosis. Colour optic nerve head photographs were taken at each topographic examination with a Topcon Imagenet-2000 fundus camera.

The pupils were dilated for laser treatment with phenylephrine $\mathrm{HCl} 2.5 \%$ and cyclopentolate $\mathrm{HCl} 1 \%$ drops, applied three times during a 30 minute period. All patients had a pupil diameter greater than $8 \mathrm{~mm}$. Both eyes of all of the patients, whether laser treated or not, had all topographic exams performed under maximum pupillary dilatation.

Both eyes of all patients underwent optic nerve head topographic examinations within 30 minutes of laser treatment. All fellow non-treated eyes received neither laser treatment nor retrobulbar injection. They underwent the same optic nerve head topographic examinations. Each patient, within 60 minutes of finishing his/her focal argon blue-green photocoagulation therapy, had the topographic examinations repeated by the same experienced observer (YA). Focal pattern laser procedures were performed with 3861 argon blue-green $100 \mu \mathrm{m}$ laser spots, with a power of $100 \mathrm{~mW}$ each. All focal argon green photocoagulation treatments were performed by one experienced ophthalmic laser surgeon (YA).

Before the focal laser treatments, 49 patients required a retrobulbar anaesthesia block (using a 1:1 mixture of $0.75 \%$ bupivacaine and 2\% lidocaine with hyaluronidase 0-7.5 IU/ $\mathrm{ml}$ in equal volumes to a total of $7 \mathrm{ml}$ ). Within 5 minutes of the block, extraocular movements of these eyes were satisfactorily restricted in all fields of gaze. None of the subjects had oedema or ecchymosis of the eyelids.

The optic nerve head analysis of all eyes was performed using a scanning laser ophthalmoscope, HRT II (Heidelberg retinal tomography II, software version 1.5, Heidelberg Engineering, Heidelberg, Germany). All images were acquired using $15^{\circ}$ field of view. The region of interest in the mean topographic images was defined by a contour line, drawn by the same operator (YA) by determining 6-8 separate points to approximate the best margin of the optic disc (inner edge of Elschnig's scleral ring). ${ }^{8}$ Magnification error was corrected using keratometry values for each individual. The topography standard deviation, disc area $\left(\mathrm{mm}^{2}\right)$, and a total of 12 stereometric parameters are calculated with HRT II. The parameters were cup area $\left(\mathrm{mm}^{2}\right)$, rim area $\left(\mathrm{mm}^{2}\right)$, cup volume $\left(\mathrm{mm}^{3}\right)$, rim volume $\left(\mathrm{mm}^{3}\right), \mathrm{cup} /$ disc area ratio, linear cup/disc ratio, mean cup depth (mm), maximum cup depth (mm), cup shape measure, height variation contour $(\mathrm{mm})$, mean retinal nerve fibre layer thickness $(\mathrm{mm})$, and retinal nerve fibre layer cross sectional area $\left(\mathrm{mm}^{2}\right)$.

Statistical analysis of the study was performed using Student's $t$ test, repeated measures of analysis of variance and descriptive statistics. Statistical significance was set as $\mathrm{p}<0.05$.

\section{RESULTS}

The mean ages of the patients who underwent focal laser treatment with $(\mathrm{n}=49)$ and without $(\mathrm{n}=46)$ retrobulbar anaesthesia were 37.7 (SD 3.1) years ( range 33-46 years) and 38.1 (3.3) years (range 32-47 years), respectively $(\mathrm{p}>0.05)$. Their mean refractive errors were -0.63 (1.01) D (range $-4.25 \mathrm{D}$ to $+2.75 \mathrm{D})$ and $0.52(0.93) \mathrm{D}$ (range $-4.00 \mathrm{D}$ to $+3.00 \mathrm{D})$, respectively $(\mathrm{p}>0.05)$. Their mean durations of diabetes were 4.9 (1.7) years and 5.3 (1.6) years $(\mathrm{p}>0.05)$. Their mean disc areas were $2.13(0.45) \mathrm{mm}^{2}$ and $2.11(0.42)$ $\mathrm{mm}^{2}$, respectively $(\mathrm{p}>0.05)$. A total of one, two, four, seven, and 12 laser treated patients with retrobulbar anaesthesia, and a total of three, four, seven, nine, and 11 laser treated patients without retrobulbar anaesthesia were lost to follow up in the first hour study, first day, the first week, the second week, and the fourth week examinations, respectively.

All eyes which were treated with laser without retrobulbar anaesthesia, and all fellow eyes which received neither laser nor retrobulbar anaesthesia, were found not to reveal any significant changes in any of the optic nerve head

Table 1 Changes in optic nerve head topography of laser treated eyes 1 hour, 1 day, and 1 week after retrobulbar anaesthetic injection

\begin{tabular}{lllll}
\hline Variables & Baseline $(\mathbf{n = 4 9 )}$ & 1st hour $(\mathbf{n = 4 8 )}$ & 1st day $(\mathbf{n = 4 7 )}$ & 1st week $(\mathbf{n}=45)$ \\
\hline Disc area $\left(\mathrm{mm}^{2}\right)$ & $2.13(0.05)$ & $2.18(0.07)^{*}$ & $2.20(0.10)^{*}$ & $2.17(0.08)^{*}$ \\
Cup area $\left(\mathrm{mm}^{2}\right)$ & $0.58(0.35)$ & $0.54(0.38)^{*}$ & $0.53(0.39)^{*}$ & $0.55(0.37)^{*}$ \\
Rim area $\left(\mathrm{mm}^{2}\right)$ & $1.55(0.34)$ & $1.64(0.39)^{*}$ & $1.67(0.39)^{*}$ & $1.62(0.35)^{*}$ \\
Cup volume $\left(\mathrm{mm}^{3}\right)$ & $0.14(0.16)$ & $0.12(0.17)^{*}$ & $0.11(0.19)^{*}$ & $0.12(0.15)^{*}$ \\
Rim volume $\left(\mathrm{mm}^{3}\right)$ & $0.47(0.19)$ & $0.51(0.22)^{*}$ & $0.53(0.21)^{*}$ & $0.50(0.20)^{*}$ \\
Cup/disc area ratio & $0.27(0.12)$ & $0.25(0.15)^{*}$ & $0.24(0.16)^{*}$ & $0.25(0.14)^{*}$ \\
Linear cup/disc ratio & $0.31(0.13)$ & $0.27(0.15)^{*}$ & $0.25(0.16)^{*}$ & $0.28(0.13)^{*}$ \\
Mean cup depth (mm) & $0.29(0.13)$ & $0.26(0.15)^{*}$ & $0.25(0.16)^{*}$ & $0.26(0.15)^{*}$ \\
Maximum cup depth (mm) & $0.78(0.31)$ & $0.72(0.35)^{*}$ & $0.70(0.33)^{*}$ & $0.73(0.32)^{*}$ \\
Cup shape measure & $-0.17(0.09)$ & $-0.20(0.11)^{*}$ & $-0.22(0.12)^{*}$ & $-0.19(0.09)^{*}$ \\
Height variation contour (mm) & $0.56(0.16)$ & $0.57(0.17)$ & $0.58(0.17)$ & $0.57(0.16)$ \\
Mean RNFL thickness (mm) & $0.32(0.11)$ & $0.32(0.12)$ & $0.31(0.13)$ & $0.32(0.12)$ \\
RNFL cross sectional area $\left(\mathrm{mm}{ }^{2}\right)$ & $1.37(0.41)$ & $1.37(0.42)$ & $1.36(0.40)$ & $1.37(0.41)$ \\
\hline
\end{tabular}

Statistical significance was set as $p<0.05$. ${ }^{*} p<0.05$.

RNFL, retinal nerve fibre layer. 
Table 2 Changes in optic nerve head topography of laser treated eyes 2 weeks and 4 weeks after retrobulbar anaesthetic injection

\begin{tabular}{llll}
\hline Variables & Baseline $(\mathbf{n = 4 9 )}$ & 2nd week $(\mathbf{n = 4 2 )}$ & 4th week $(\mathbf{n}=\mathbf{3 7})$ \\
\hline Disc area $\left(\mathrm{mm}^{2}\right)$ & $2.13(0.05)$ & $2.14(0.07)$ & $2.13(0.06)$ \\
Cup area $\left(\mathrm{mm}^{2}\right)$ & $0.58(0.35)$ & $0.55(0.38)^{*}$ & $0.58(0.36)$ \\
Rim area $\left(\mathrm{mm}^{2}\right)$ & $1.55(0.34)$ & $1.59(0.35)^{*}$ & $1.54(0.34)$ \\
Cup volume $\left(\mathrm{mm}^{3}\right)$ & $0.14(0.16)$ & $0.13(0.17)$ & $0.14(0.17)$ \\
Rim volume $\left(\mathrm{mm}^{3}\right)$ & $0.47(0.19)$ & $0.48(0.20)$ & $0.47(0.20)$ \\
Cup /disc area ratio & $0.27(0.12)$ & $0.26(0.14)$ & $0.27(0.13)$ \\
Linear cup/disc ratio & $0.31(0.13)$ & $0.31(0.15)$ & $0.30(0.13)$ \\
Mean cup depth (mm) & $0.29(0.13)$ & $0.28(0.14)$ & $0.29(0.14)$ \\
Maximum cup depth (mm) & $0.78(0.31)$ & $0.78(0.32)$ & $0.79(0.31)$ \\
Cup shape measure & $-0.17(0.09)$ & $-0.20(0.10)^{*}$ & $-0.17(0.09)$ \\
Height variation contour (mm) & $0.56(0.16)$ & $0.57(0.17)$ & $0.57(0.16)$ \\
Mean RNFL thickness (mm) & $0.32(0.11)$ & $0.32(0.13)$ & $0.31(0.12)$ \\
RNFL cross sectional area (mm $\left.{ }^{2}\right)$ & $1.37(0.41)$ & $1.37(0.39)$ & $1.36(0.40)$ \\
\hline Statistical significance was set as $\mathrm{p}<0.05 .{ }^{*} \mathrm{p}<0.05$. & & \\
RNFL, retinal nerve fibre layer. & & & \\
\hline
\end{tabular}

topographic examination during the 4 week study period (all $\mathrm{p}$ values $>0.05$ ) .

Those eyes that underwent laser treatment after retrobulbar anaesthesia (n:49) demonstrated significant increase in the disc area, rim area, rim volume, rim area/disc area and cup shape measure parameters, while they demonstrated significant decrease in linear cup to disc ratio, cup area/disc area, cup area and cup volume parameters in the first hour, first day and the first week topographic examinations, (all p values $<0.05$ ) (table 1 ). In the second week examinations, disc area measurements were not significantly different from baseline $(\mathrm{p}>0.05)$ (table 2 ). However, there were statistically significant differences in rim area, cup area, and cup shape measurements from baseline (table 2). By the fourth week, all of the optic nerve head topographic variables were not significantly different from the pre-injection values (table 2).

None of the patients received additional retinal laser therapy during the study period. By the end of the fourth week, six (in injection group) and seven (in non-injection group) patients demonstrated some degree of improvement in macular oedema ophthalmoscopically with significant increases in visual acuity. There were no visually detectable changes in clinically significant macular oedema in the rest of the patients, and no significant change in visual acuity. No patient developed any laser related complication or optic neuropathy after focal laser treatment. Representative colour optic nerve head photographs of multiple examination points for all patients were evaluated by two experienced examiners (masked to the cases). No evidence of optic nerve head oedema or blurring of the disc margins was noted in any of them. The eyes that underwent laser treatment with retrobulbar anaesthesia demonstrated a significant change in intraocular pressure, with a mean increase of $6.7 \mathrm{~mm} \mathrm{Hg}$, 1 hour after retrobulbar injection $(\mathrm{p}<0.05)$. The intraocular pressure in other examinations were not found to be different from baseline $(p>0.05)$. The rest of the eyes in the study did not show any significant changes in intraocular pressure in any of the examination points (all p values, $>0.05$ ).

\section{DISCUSSION}

The visual loss after retrobulbar haemorrhage has been attributed to the acute compression of the optic nerve by the haemorrhage, or optic neuropathy caused by the direct effect of blood degrading products on the optic nerve. 9 Here, we studied the effects of acute orbital volume increase by retrobulbar anaesthetic injection on optic nerve head topography during a 4 week period. We enrolled diabetic patients who did or did not undergo retrobulbar anaesthetic injection for anaesthesia during focal pattern retinal photocoagulation. The current study was designed to simulate a model of optic nerve head effects following mild acute intraorbital volume increase.

We found that acute volume change in the orbit caused by a retrobulbar injection of as much as $7 \mathrm{ml}$ anaesthetic can potentially lead to a small, clinically not detected and reversible disc oedema. Significant changes in optic rim and cup area may last for 2 weeks after injection, with all topographic changes returning to baseline by 1 month after injection. Regional orbital anaesthesia has been associated with acute haemodynamic changes, including reduction in blood flow velocity, increased resistive index in the central retinal artery, ${ }^{10}$ and decreased ocular perfusion. ${ }^{11}$ Loken et al reported that electroretinogram is significantly reduced and delayed in patients during regional anaesthesia of the orbit. ${ }^{12}$

During the first 2 weeks after injection, laser treated eyes which received retrobulbar injection demonstrated significant increase in the rim area, rim area/disc area, and rim volume parameters while they showed significant decrease in optic cup parameters. Changes in rim and optic cup parameters may result from the temporary optic disc oedema. However, significant changes in these parameters lasted for one additional week after the optic disc area normalised.

Beside the optic cup and rim parameters, none of the other optic nerve head topographic parameters (other than cup shape measure) was significantly affected by the retrobulbar injection. Topouzis et al, in their HRT study on 25 glaucomatous patients undergoing trabeculectomy, showed that changes in the optic disc that may be present 2 weeks after a trabeculectomy do not appear to persist up to 4 months later, other than cup shape measure, which was still different from preoperative values at 4 months but not at 8 months. ${ }^{13}$ Durukan et al, in their study on normal population using HRT II, found that cup shape measure was the only topographic parameter which is not associated with disc area, age, sex, laterality, refractive error, and any other topographic parameter. ${ }^{8}$

Meyer et al claimed that the presence of $10.5 \mathrm{ml}$ of fluid in the retrobulbar and peribulbar space did not significantly affect the IOP of the anaesthetised eye. ${ }^{10}$ In the current study, each laser treated patient who required retrobulbar block for ocular akinesia, received a volume of $7 \mathrm{ml}$ retrobulbar anaesthetic injection including lidocaine $\mathrm{HCl} 2 \%$ with adrenaline (epinephrine) and bupivacaine $0.75 \%$ in equal volumes. Immediately after retrobulbar injection, we found that the intraocular pressure increased significantly with a mean change of $6.7 \mathrm{~mm} \mathrm{Hg}$. Jay et al reported a mean increase in intraocular pressure of $4.4 \mathrm{~mm} \mathrm{Hg}$ soon after completion of retrobulbar injection. ${ }^{14}$ Palay and Stulting found an average rise in intraocular pressure of $6.2 \mathrm{~mm} \mathrm{Hg}$ after retrobulbar injection of $4 \mathrm{ml}$ of anaesthetic. ${ }^{15}$ 
None of our patients had an intraocular pressure measuring more than $25 \mathrm{~mm} \mathrm{Hg}$ immediately after the injection. Following retrobulbar haematoma, visual loss can be detected even in cases with intact retinal circulation. ${ }^{16}$ In these cases, visual loss can be explained from optic nerve ischaemia. Occlusion of the short posterior ciliary artery may result in optic nerve infarction. ${ }^{16}$ However, ophthalmoscopic examination performed immediately after our injections failed to reveal any retinal or vascular complication in any of the cases. Therefore, we speculate that any difference in optic nerve head topography most likely resulted from the effects of the anaesthetic agent on intraorbital volume.

We applied focal laser application to the microaneurysms temporal to the fovea. Previous studies reported the effect of focal laser on retinal thickness and visual field. But these are relatively minor, and occur late. ${ }^{17-19}$ Shahidi et al, using optical coherence tomography, showed that retinal thickness decreased in $50 \%$ and remained unchanged in 36\% of thickened locations 4 months after treatment, and new areas of thickening developed in 3\% of the locations. ${ }^{17}$ Sims et al suggested that focal photocoagulation treatment produced small absolute scotomas in the treated regions of the visual field based on the statistically significant increase in the mean deviation compared to the untreated region of the field. ${ }^{19}$ However, threshold changes were small, less than $4 \mathrm{~dB}$, and whole fields appeared essentially unchanged. ${ }^{19}$ In the current study, we found that laser treated eyes, which did not receive retrobulbar injection, and fellow eyes, which did not receive either laser or retrobulbar anaesthesia, did not demonstrate any significant changes in optic nerve head topography. Therefore, we speculate that changes seen in optic nerve head topography in the current study most probably resulted from the volume effect of retrobulbar anaesthesia rather than focal laser photocoagulation treatment.

Owing to the limited capacity for expansion, increased volume because of haemorrhage results in increased pressure and compression of contained structures. ${ }^{5}$ The optic nerve may be compressed directly, or the vascular supply to the nerve may be compromised. ${ }^{5}$ We injected $7 \mathrm{ml}$ of retrobulbar anaesthetic solution in 49 patients who required retrobulbar block.. Total volume of the orbital contents varied between $23.6 \mathrm{ml}$ to $27.1 \mathrm{ml}^{20}{ }^{21}$ The mean volume of the globe was found to be $7 \mathrm{ml}$ for females and $7.5 \mathrm{ml}$ for males. ${ }^{22}$ The present study demonstrates that an increase in orbital volume of $7 \mathrm{ml}$ may potentially cause subclinical optic disc oedema. This finding may give some insight as to what happens after a mild retrobulbar haemorrhage following trauma.

In summary, optic nerve head topographic changes seen in eyes which underwent focal laser photocoagulation treatment after receiving retrobulbar block seems to result from the retrobulbar block rather than laser treatment itself. Acute collection of even less fluid confined in the retrobulbar space may cause significant optic disc oedema together with significant changes in optic rim and cup parameters of the optic nerve head. These should be taken into consideration in the clinical evaluation, treatment, and follow up of patients who underwent orbital trauma with retrobulbar haemorrhage.

\section{ACKNOWLEDGEMENT}

This study was supported by Akdeniz University Scientific Research Projects Unit.

\section{Authors' affiliations}

Y Akar, K C Apaydin, A Ozel, Akdeniz University, School of Medicine, Department of Ophthalmology, Antalya-Turkey

\section{REFERENCES}

1 Wollstein G, Garway-Heath DF, Hitchings RA. Identification of early glaucoma cases with the scanning laser ophthalmoscope. Ophthalmology 1998; 105: 1557-63.

2 lester M, Mikelberg FS. Optic nerve head morphologic characteristics in hightension and normal-tension glaucoma. Arch Ophthalmol 1999;117:1010-13.

3 Caprioli J. Clinical evaluation of the optic nerve in glaucoma. Trans Am Ophthalmol Soc 1994;92:589-641.

4 Quigley HA, Katz J, Derick RJ, et al. An evaluation of optic disc and nerve fiber layer examinations in monitoring progression of early glaucoma damage. Ophthalmology 1992;99:19-28.

5 Vassallo $S$, Hartstein M, Howard D, et al. Traumatic retrobulbar hemorrhage: emergent decompression by lateral canthotomy and cantholysis. J Emerg Med 2002;22:251-6.

6 Early Treatment Diabetic Retinopathy Study Research Group. Photocoagulation for diabetic macular edema. Early Treatment Diabetic Retinopathy Study report number 1. Arch Ophthalmol 1985;103:1796-806.

7 Lobo CL, Bernardes RC, de Abreu JR, et al. One-year follow-up of bloodretinal barrier and retinal thickness alterations in patients with type 2 diabetes mellitus and mild nonproliferative retinopathy. Arch Ophthalmol 2001;119:1469-74.

8 Durukan AH, Yucel I, Akar Y, et al. The assessment of the optic nerve head topographic parameters with a confocal scanning laser ophthalmoscope. Clin Experiment Ophthalmol 2004;32:143-9.

9 Mahaffey PJ, Wallace AF. Blindness following cosmetic blepharoplasty-a review. Br J Plast Surg 1986;39:213-21.

10 Meyer D, Hamilton RC, Loken RG, et al. Effect of combined peribulbar and retrobulbar injection of large volumes of anesthetic agents on the intraocular pressure. Can J Ophthalmol 1992;27:230-2.

11 Hessemer V, Wieth K, Heinrich A, et al. Changes in uveal and retinal hemodynamics caused by retrobulbar anesthesia using various injection volumes. Fortschr Ophthalmol 1989;86:760-6.

12 Loken RG, Coupland SG, Deschenes MC. The electroretinogram during orbital compression following intraorbital regional block for cataract surgery. Can J Anaesth 1994;41:802-6.

13 Topouzis F, Peng F, Kotas-Neumann R, et al. Longitudinal changes in optic disc topography of adult patients after trabeculectomy. Ophthalmology 1999; 106:1147-51

14 Jay WM, Carter H, Williams B, et al. Effect of applying the Honan intraocular pressure reducer before cataract surgery. Am J Ophthalmol 1985; 100:523-7.

15 Palay DA, Stulting RD. The effect of external ocular compression on intraocular pressure following retrobulbar anesthesia. Ophthalmic Surg 1990;21:503-7.

16 Pelit A, Haciyakupoglu G, Zorludemir S, et al. Preventative effect of deferoxamine on degenerative changes in the optic nerve in experimental retrobulbar haematoma. Clin Experiment Ophthalmol 2003;31:66-72.

17 Shahidi M, Ogura Y, Blair NP, et al. Retinal thickness change after focal laser treatment of diabetic macular oedema. Br J Ophthalmol 1994;78:827-30.

18 Rivellese M, George A, Sulkes D, et al. Optical coherence tomography after laser photocoagulation for clinically significant macular edema. Ophthalmic Surg Lasers 2000;31:192-7.

19 Sims LM, Stoessel K, Thompson JT, et al. Assessment of visual field changes before and after focal photocoagulation for clinically significant diabetic macular edema. Ophthalmologica 1990;200:133-41.

20 Adenis JP, Robert PY, Boncoeur-Martel MP. Abnormalities of orbital volume. Eur J Ophthalmol 2002; 12:345-50.

21 Forbes G, Gehring DG, Gorman CA, et al. Volume measurements of normal orbital structures by computed tomographic analysis. Am J NeuroRadiol 1985;6:419-24.

22 Hintschich CR, Bonneveld FW, Bunce C, et al. Volumetry of bony and soft tissue compartments in the enucleated human orbit. Br J Ophthalmol, $2001 ; 85,2: 205-8$. 